\section{Cancer treatment-} induced menopause: Meaning for breast and gynecological cancer survivors

by Christine S. Davis, Jeanie E. Zinkand, and Margaret I. Fitch

\begin{abstract}
Many cancer survivors are faced with irreversible changes resulting from cancer treatment. One such change some women face after cancer is treatment-induced menopause. Eight women (four with breast and four with gynecological cancers) were interviewed to explore the impact of treatment-induced menopause on their lives. Results indicated that participants' understanding and coping with menopause occurred within the larger context of the total cancer experience. For some of the women, menopause was not a significant problem; for others, the symptoms caused major distress and were a continuing reminder of the losses suffered due to cancer. Important concerns for all participants were: taking and keeping control, the desire to return to "normal" after cancer, and maintaining a coherent sense of self. Strong statements were also made about the power of knowing and the power of support in coping with treatment-induced menopause. Findings are discussed with implications for nursing practice.
\end{abstract}

Key words: treatment-induced menopause, cancer, survivorship, women's health, psychosocial support

An increasing number of people with cancer experience long periods of remission and/or a time when no evidence of disease exists. Studies in this area (Cella, 1987; Cella \& Tross, 1986; Tross, Holland, Bosl, \& Geller, 1984) suggest that cancer survivors can have a number of long-term problems in adjustment. Many survivors are faced with irreversible changes resulting from their cancer treatment and with the physical and emotional aftermath of these changes. For some, the psychosocial issues surrounding the long-term consequences of cancer treatment emerge a number of months or even years after their treatment has been completed.

One irreversible change faced by some women survivors is treatment-induced menopause. Certain types of surgery (total hysterectomy with oophorectomy), chemotherapy with alkylating agents, and/or radiation to the pelvic area lead to alterations in ovarian function for the majority of women who receive these cancer treatments. Women at particular risk for treatment-induced menopause include those being treated for breast or gynecological cancers (Pritchard, 1996). Moreover, there is reason to believe that the number of women affected in this way is increasing due to recommendations for wide-scale use of adjuvant chemotherapy and hormonal treatments in node-negative breast cancer (Canney \& Hatton, 1994). Hubner (1989) points out that these women are faced with a new level of decisionmaking, having to weigh "the statistical risk of recurrence, the impact of adjuvant chemotherapy in ameliorating that risk, and the potential damage to reproductive function of adjuvant chemotherapy" (p.6).

\section{Literature review}

Normal vs. treatment-induced menopause

Under normal circumstances, menopause occurs for most women during middle age (around age 50). The range of symptoms accompanying menopause has been clearly documented (Brener, 1988). Reports indicate that about $75 \%$ of menopausal women experience vasomotor responses, and that half of these women find the symptoms acutely uncomfortable (Dewhurst, 1976). Estrogen replacement therapy (ERT) is frequently the treatment of choice for managing the vasomotor symptoms, although it may have little effect on the psychological and behavioural symptoms that interfere with daily living.

Women who experience menopause as a result of their cancer treatment do so "prematurely." Moreover, the symptoms of treatmentinduced menopause appear suddenly in contrast to the gradual onset of natural menopause, and there are indications that this rapid onset may result in more severe symptoms (Hubner, 1989; Shover, 1988). In what is considered a landmark study, Chapman, Sutcliffe, and Malpas (1979) reported that only $17 \%$ of the 41 women who received combination chemotherapy (MVPP) for advanced Hodgkin's disease maintained ovarian function. Three-fifths $(n=25)$ of the women had complete amenorrhea with evidence of premature ovarian failure, and only five had regular menstrual cycles. Madsen and colleagues (Madsen, Giudice, \& Donaldson, 1995), however, report little risk of premature menopause when treatment is radiation alone, excluding the pelvis.

\section{ABRÉGÉ}

\section{MÉNOPAUSE INDUITE PAR LE TRAITEMENT DU CANCER : SIGNIFICATION POUR LES SURVIVANTES DU CANCER DU SEIN ET DE CANCERS GYNÉCOLOGIQUES}

De nombreuses survivantes du cancer doivent faire face aux changements irréversibles provoqués par les traitements antinéoplasiques. Chez certaines femmes, il s'agit de la ménopause induite par le traitement du cancer. On a réalisé des entrevues auprès de huit femmes (quatre atteintes du cancer du sein et quatre de cancers gynécologiques) afin d'explorer l'impact, sur leur vie, de la ménopause induite par le traitement du cancer. Les résultats indiquent que la compréhension qu'en avaient les participantes et leur adaptation se produisaient dans le plus large contexte du vécu global du cancer. Pour certaines des femmes, la ménopause ne constituait pas un problème de taille; par contre, pour d'autres, les symptômes entraînaient une grave détresse et leur rappelaient constamment les pertes inhérentes à leur maladie. Toutes les participantes signalaient les grandes préoccupations suivantes : prendre le contrôle et le maintenir, désir de revenir à un état "normal" après la maladie, maintenir une image cohérente de soi. Elles ont également souligné l'important pouvoir de la connaissance et du soutien au niveau de l'adaptation à la ménopause induite par le traitement du cancer. On discute des résultats et on présente les répercussions pour la pratique infirmière. Mots clés : ménopause induite par le traitement du cancer, cancer, survivantes du cancer, santé des femmes, soutien psychosocial.

Christine $\mathrm{S}$. Davis, $\mathrm{PhD}$, is a psychologist at the William Osler Health Centre in Brampton, Ontario.

Jeanie E. Zinkand, MSW, and Margaret I. Fitch, RN, PhD both work at

the Toronto-Sunnybrook Regional Cancer Centre, Toronto, Ontario. 
Averette, Boike, and Jareel (1990) noted that menopausal effects may be age-dependent, with women over age 30 showing a dramatic increase in menstrual irregularities. Bianco et al. (1991) reported on an investigation of adjuvant chemotherapy in premenopausal women with early breast cancer. They found that continuing amenorrhea occurred in $63 \%$ of the patients studied and that age was a significant factor. The older the woman, the higher the incidence of drug-induced amenorrhea, the shorter the time to produce it, and the less likely for the symptoms to be temporary. Anderson (1985) noted that early stage cervical cancers, ovarian, and endometrial cancers are treated similarly with radiation therapy or radical hysterectomy which affect not only ovarian function, but also lead to a variety of changes in vaginal structure that further impair sexual functioning and enjoyment.

Unfortunately, many of the women experiencing treatmentinduced menopause do not have the option of ERT because of their type of cancer tumour, e.g., breast cancer patients with estrogensensitive tumours (Bachmann, 1994; Couzi, Helzlsouer, \& Fetting, 1995; Snyder, Sielsch, \& Reville, 1998). In addition, some studies have indicated that long-term ERT is associated with an increased rate of endometrial cancer and breast cancer recurrence (Atunes et al., 1979). Moreover, ERT has a very limited effect on women who have received extensive pelvic radiation because vaginal tissues are often permanently damaged and, thus, left unable to respond to hormonal influences (Anderson, 1985).

The full impact of treatment-induced menopause is likely to emerge most clearly following the completion of cancer treatment when the immediate "crisis" of diagnosis and treatment has subsided. Women with treatment-induced menopause may feel "out of sync" with their peers, not only because they are dealing with the stresses of a major illness, but also because they are facing a normal life event at the "wrong" time. One young woman described this experience as "waking up one morning to find that you have just turned 65." Psarakis, Devlin, and Beckerson (1990) point out that it is this additivity of events and deviation from expected timing that can significantly increase the level of psychological distress experienced.

\section{Psychosocial impact of treatment-induced menopause}

There is a paucity of literature regarding the cancer survivor's experience of treatment-induced menopause, although a growing literature is available regarding the broader issues of sexual functioning and psychosocial effects (McPhail, 1999). In a study of women with cancer treatment-induced menopause, Moadel, Ostroff, Lesko, and Bajorunas (1995) found that the severity of menopausal symptoms and problems in relationship adjustment were the best predictors of sexual dysfunction. Schiam (1985) notes that menopausal changes affect sexuality not only because of the physiological symptoms, but also because of the psychological interpretation attached to them. Women with treatment-induced menopause may experience disruption in body image (Anderson, 1985; Anderson \& Hochler, 1983), feelings that they are empty or incomplete (Jamison, Wellisch, \& Pasnau, 1978), and a diminished sense of femininity (Anderson \& Hochler, 1983). All of this may result in a withdrawal from sexual intimacy. Our clinical experience suggests that, for at least some women, the psychosocial impact of treatment-induced menopause extends well beyond the area of sexuality. Fatigue, depression, and mood fluctuations are seen as significantly affecting the ability to return to an active career or the demands of a young family. Changes in self-image are viewed as contributing to impairment in existing relationships and to the inability to establish new ones. These less obvious consequences are not well documented.

While the symptoms of normal menopause are well known, the full range of problems and concerns experienced by women who have become prematurely menopausal as a result of their cancer treatment is poorly understood, as are many late effects of cancer treatment (Fenlon, 1995; Tamlyn-Leaman, 1995). The present study was undertaken to: 1) document women's experiences with cancer treatment-induced menopause, the nature of any changes, and women's responses to those changes, and 2) to identify common issues, concerns, or problems if they exist.

\section{Method}

A qualitative approach was used since the focus was on documenting, as completely as possible, the experiences and difficulties associated with treatment-induced menopause.

\section{Participants}

Participants were recruited from women in follow-up for breast cancer and gynecological cancer, and selection was based on the following criteria: 1) the patient had completed active treatment for cancer; 2) had been treated for primary disease and had not experienced recurrence; 3) was premenopausal prior to cancer treatment, that is, her last normal menses occurred within six weeks preceding the beginning of therapy (Bianco et al., 1991); and 4) was currently not experiencing spontaneous menstruation. In addition, we also required that patients were at least six months post-treatment and had experienced the cessation of spontaneous menstruation for at least six months as a result of cancer treatment. We were interested in difficulties women were experiencing, so we attempted to recruit patients who complained of fatigue, mood fluctuations, decreased vigour, sexual difficulties, or other concerns that interfered with their ability to return to normal activities at home or work. These criteria were designed to identify women with well-established, treatmentinduced menopause who were experiencing psychosocial difficulties at a time when active disease and treatment were no longer primary issues, recognizing that the results will not apply to all women.

\section{Procedure}

Following approval of the study by the ethical committee of the health science centre, participants were identified by primary nurses within the clinical setting, and informed consent was obtained. Participants were interviewed at their convenience in the setting of their choice (home or clinic). All interviews were conducted by either the principal investigators or a Masters of Arts psychology student. The four interviewers had extensive experience in qualitative approaches and together developed the interview guide.

Interviews were audio-recorded and were approximately one hour in length. The interview format was designed to be relatively unstructured, allowing the participants to provide a natural history of their experiences, in their own words, and with their own order of importance and meaning. Guidelines for the interview ensured that specific issues thought to be associated with treatment-induced menopause (e.g., problems in intimacy, returning to normal activities, energy level, and concentration, as well as physical symptoms) were addressed at some point in the interview.

\section{Data analysis}

The taped interviews were transcribed verbatim. All the interviews were read by the three principal investigators who made marginal notes on each interview, compared their observations, and developed a category system. Once the interviews were re-read and coded, the coded data were used to generate themes (Collaizzi, 1978). The different disciplinary perspectives of the investigators helped to maintain an important dialogue regarding the full meaning of each theme.

\section{Results}

\section{Participant demographics}

Participant demographics are summarized in Table One. We were not able to make any clear distinction among participants based solely on demographic or disease variables. It was our impression that a stronger component in differentiating their accounts was the general way in which these women made sense of both their disease and 
treatment-induced menopause within their life context. The women seemed to present their experience from four perspectives.

First, four of the women (in long-term marriages, with children) shared a strong determination to "get on with their lives," to find the good things in their cancer experience, and perhaps even to improve their lives because of that experience. In contrast, two of the women (also in long-term relationships, with children) were still having important difficulties associated with their cancer experience. Treatment and its effects (including menopause) continued to be problematic for them and coloured their life view in a more negative way. The youngest participant, who was recently married and had no children, was struggling with the loss of fertility and the impact this had on her plans for the future and her feelings about the past opportunities she had lost. Finally, one woman stood out because of the cultural dimension in her account. Although she was similar to the women in our first group in her resolve to be strong and positive, she also was unique in her perspective on menopause as it affected her identity as a woman (an impact that seemed, at least in part, culturally grounded). The presentation of the major themes which emerged from the data analysis focuses on five major content domains: the cancer experience; the menopause experience; "getting through" cancer and its effects; the power of knowing; and the power of support. The first two domains document the experience of our participants with their illness, its treatment, and the menopause that followed. The remaining three domains focus on the emotional, psychological, and interpersonal dimensions associated with these experiences and form the core of the "survival" process.

\section{The cancer experience}

All participants spoke about the difficulties and disappointments associated with their illness and tended to downplay the impact of treatment-induced menopause. For all participants, the course of illness began with the experience of "discovery," often with a description of an internal knowing, a dawning recognition and fear that pre-dated the actual medical diagnosis. Several women spoke of the faith they had in medical tests and physicians which was shaken by the delays in and missed diagnoses that were sometimes part of the discovery process. Each woman had her own unique set of past experiences with cancer, and unique expectations based on personal and family history with the disease.

The descriptions of the course of treatment were vivid and emotionally powerful. One woman remembered, “...to suddenly be so vulnerable, the physical lying on a radiation table with no clothes on, and people standing around just chatting about anything."

These women often related a process that seemed to move with a life of its own and over which they felt they had little control. It often felt to them that decisions had to be made very quickly, that they were confused about their options, and ill-prepared for what would follow. The "disappointments" associated with the cancer experience included all the physical and psychological losses suffered as a result of treatment, as well as the sense that they had lacked the preparation, knowledge, and support necessary to get through the treatment process in the best way possible:

But also I did a lot of reading on it. But the more I read the more I worried and thought, I've got to stop reading because I'm scaring myself and I just have to trust the doctors. And yet you hear cases where doctors make mistakes, so then you think, well I've got to be informed and look for symptoms or whatever in case they've missed something.

All participants spoke of the important self-discoveries and personal triumphs that emerged out of their illness. Some of these women discovered previously unrecognized personal courage, strength and values; some came to see themselves as in control and not helpless victims. The experience of support from others was a factor that many of our participants saw as essential in getting through treatment and beginning to heal. Some felt they had indeed been victorious over their disease and were well along in a healing process:

I just wanted to fight this thing and get on with it... realizing that I could handle something like this, that I could be strong enough.... it just brought me a lot of courage and you just realize how precious life is.

\section{The menopause experience}

The experiences associated with treatment-induced menopause, as

Table One: Participant demographics

\begin{tabular}{|c|c|c|c|c|c|c|}
\hline & Age & Marital status & Children & Work & Treatment & Post-treatment \\
\hline \multicolumn{7}{|c|}{ Breast cancer } \\
\hline 1 & 43 & $\begin{array}{l}\text { Divorced; } \\
\text { long-term } \\
\text { relationship }\end{array}$ & 2 (teens) & Full-time & lumpectomy, chemotherapy & 6 months \\
\hline 2 & 45 & Divorced & 1 (teen) & Full-time & mastectomy & 6 months \\
\hline 3 & 41 & $\begin{array}{l}\text { Married } \\
(20 \text { yrs })\end{array}$ & $\begin{array}{l}2(12 \mathrm{yrs} \\
71 / 2 \mathrm{yrs})\end{array}$ & Homemaker & mastectomy, chemotherapy, radiation & 6 months \\
\hline 4 & 57 & $\begin{array}{l}\text { Divorced; } \\
\text { remarried ( } 8 \text { yrs) }\end{array}$ & 1 (adult) & Full-time & mastectomy, chemotherapy & 6 years \\
\hline \multicolumn{7}{|c|}{ Gynecological cancer } \\
\hline 5 (uterine) & 50 & Married (23 yrs) & 2 (adult) & Full-time & radiation, hysterectomy, premarin & 6 months \\
\hline 6 (ovarian) & 33 & Married (1 yr) & - & Full-time & $\begin{array}{l}\text { hysterectomy, chemotherapy, } \\
\text { estrogen replacement therapy }\end{array}$ & 3 years \\
\hline 7 (ovarian) & 36 & Married (12 yrs) & $\begin{array}{l}4(4,6,7 \\
12 \text { yrs })\end{array}$ & Full-time & $\begin{array}{l}\text { hysterectomy bilateral Salpingo } \\
\text { oopherectomy \& omentectomy, } \\
\text { estrogen replacement therapy }\end{array}$ & 10 months \\
\hline 8 (ovarian) & 43 & Married (24 yrs) & $\begin{array}{l}3(19, \\
17,15 \mathrm{yrs})\end{array}$ & Full-time & hysterectomy, chemotherapy, radiation & 6 months \\
\hline
\end{tabular}


reported by our participants, ranged from being mild and nonintrusive to severe and all-consuming. The changes precipitated by menopause include those that were primarily physically-based, those that were situated within the experience of intimacy with another, and those that had more meaning for a personal sense of self. Along the physical dimension, our participants reported hot flashes, sweats, itchiness, vaginal dryness, weight gain, and fatigue. They also discussed, as physically-based, mood swings and depression, memory lapses, problems sleeping, bad dreams, loss of libido, and lack of organization and concentration. One woman said, "They (mood swings) come every day and I'm having hot flashes.... There's nothing they can do for you so you're awake half the night half of the time...it's a miserable feeling."

The severity of these symptoms was not associated with any particular demographic or disease variable. A number of women reported that stress tended to make some symptoms worse and that certain environments (e.g., a hot humid room) could trigger hot flashes or sweats. Our participants documented an impressive variety of medications, home remedies, and strategies that they had tried to control their symptoms, most of which (aside from ERT) had little or no effect in relieving their discomfort:

I still have (hot flashes) now six years later but they're not as bad as they used to be...(Initially) I must have had at least one an hour, probably more than that...over several years I tried almost everything that I could think of, that I read about, and had heard about. I think I started off with vitamin $E$ and then I went to a Chinese herbalist. I tried other herbal things. My family doctor suggested Dixarit, a beta blocker, so I took that for maybe two months but it didn't do anything.

As in the other thematic domains, the dimension of "relationships with others" played a central role in understanding the impact of premature menopause and its physical changes. For example, to talk about issues in sexuality rather than issues in intimacy seems to be missing the point from our participants' perspective. One woman expressed her feelings succinctly when she observed that what she experienced was "not lack of love but lack of desire." Comfort for these women had now become discomfort; fears and anticipation of pain had become the context for sexuality. "It was very frightening the first time (post-treatment sexual intercourse). It was frightening and it was incredibly uncomfortable."

Some women spoke of their disappointment at the loss of their ability to give their husbands pleasure, and the loss of the romantic power that used to characterize their intimacy. At least one woman found that her intimate relations with her husband were still very satisfactory, and others felt that with the proper techniques and a slower, gentler approach, sexual intercourse could be pleasurable. Overall though, our sense was that couples spoke little about these problems, attempted sexual relations less frequently, and did not feel comfortable confronting the issue directly with each other or their health care providers.

Finally, treatment-induced menopause also was seen as having a diverse set of personal meanings for these women. It was often discussed in terms of losses: a lack of control; a loss of possibility, fertility, womanhood, and cherished dreams. "I guess because of my age (twenties) and I was not married, my biggest fear was the fact that I wouldn't be able to have children. I don't even think the cancer part hit me."

For some women it was seen as an area of unfinished business (an indication that the cancer experience was "not over") or was acknowledged with a sense of resignation or acceptance. "You sort of wish that you're finished, through with the whole set of treatment course. It is something that you think of every day. You try to be pleasant... but it's very unpredictable."

Some women felt they were now "out of sync" with their peers and felt confused abut how to think of themselves with their physical and psychological "selves" seemingly at different junctures. As one woman explained, "I lost something in my body. That's what I'm feeling. But sometimes I say to myself, well just forget it and just as long as you are strong, and as long as you come back, that's it." The uncertainty about whether symptoms were physically-based or more psychological in origin only served to exacerbate this confusion and ambiguity. This seemed to be, in part, because menopause was something already on the horizon, but also because, as one participant put it, "At 51 I was more confident of myself and aware of what I am and who I am."

\section{"Getting through"}

The process of discovering cancer, going through treatment, and survivorship involves not only physical demands, but also the psychological, emotional, and social changes and adjustments necessary to make sense of and live through the experience. We have called this latter aspect of the process "getting through" to denote all of the ways in which our participants navigated the course of their illness. Each woman found her own way of getting through the cancer experience; moreover, the extent to which a participant saw herself as successful was not entirely dependent on the particular path she took. One woman noted, "I realized I have to figure out why I got into this mess. Something had to change in my own life or my own attitude or something that could have precipitated it." Another participant stated, "My oncologist says you just take one day at a time and plug along as best you can, try to get through. And that's basically what I do." Three dimensions of "getting through" cancer and its effects emerged from the data analysis.

\section{Taking and keeping control}

For several women, part of getting through the cancer diagnosis and treatment was re-establishing a sense of personal control. Some of their attempts to establish control were practical and problem-focused:

Once I could also get control of my treatments and changed

some of the times, I went out for lunches (etc.) ...I continued to

keep myself overbooked .... It was better to refuse something than wonder what you were going to do, and I just got better. Taking control also meant active lifestyle changes, pursuit of alternative therapies, or changes in their relationships with others. Limits were both set and pushed, and much of this was seen as a way of taking care of oneself. "I've always just told my kids that you never give up on a dream...you just keep at it. You may have to revise or adapt, but you don't give up."

Taking control sometimes meant adopting a particular psychological stance toward illness, that is, a determination to be strong, not look back, and maintain a positive outlook. As one woman put it, "thinking positively and clearing away all the webs of fear." As noted, the experience of menopause and its associated symptoms interfered with the ability of some of our participants to feel that they were in control and could maintain an optimistic stance. This was not so much because it represented a danger to their physical well-being, but because it made them feel that permanent changes had occurred with direct consequences for their day-to-day functioning. It also served as a reminder of their cancer and an indication that they had not and would not return to "normal."

In the beginning I think I was angry I had to take it (estrogen)...maybe it was some sort of denying that I had cancer. Or not sort of accepting the fact that this is something that I have to take for the rest of my life.

\section{(Not) returning to normal}

This theme reflected the desire of some of our participants to feel that they had negotiated the experience of having cancer and that their lives had basically returned to normal. Women spoke of the need to find some acceptance of what had happened, to live life "one day at a time," and to be as well, both physically and emotionally, as they could be. "I did start going back to work (during chemo treatment) for 
two or three days a week and I did bring work home with me. I just felt like I was anxious to resume with normal life."

For other women, returning to normal activities remained problematic. They experienced resignation, rather than acceptance; loss and shattered dreams, rather than a sense of change and a new beginning. For women with continuing symptoms, menopause stood as a powerful reminder of the cancer, confronting them with the fact that it still affected their lives, and that, at best, they would learn to put up with its impact on a day-to-day basis. "Well, it's just really hard. Everything you do it affects... It's something you adjust to, but you don't like it."

The sense of loss was especially evident in the account of our youngest participant who felt that her life was curtailed in important ways by the premature menopause. She said, "Probably the bad side is that at my age I wouldn't be able to have children."

However, even for the older participants, those who had already had families, menopause represented a change in their status as women, in one case with a strong cultural overtone about the importance of menstruation as part of sexual identity. This woman said, "That's why maybe I feel I want my menstruation to come back. If possible. Really I want one more child... because my mom when she was 50 years old she still had a baby."

\section{Maintaining/changing sense of self}

Getting through cancer can be seen as a struggle to defend against a devastating attack on one's sense of self. Taking control, taking action, being positive were all ways of confirming that the self was still intact and was able to face the onslaught of cancer without losing its integrity. Some women spoke of a process of self-discovery that emerged out of their experience - a realization of just how strong they were, the depths of their courage and the values that sustained them. For some participants, the dynamic of change was even more dramatic. They had not simply maintained their sense of self, they were in the process of becoming a "new" person. This was presented as a positive development, ranging from changes in diet and lifestyle to a more profound feeling of self-healing, encompassing many basic aspects of personality and relationships. The process also seemed to involve an integration of the cancer experience, incorporating it into the new identity as an important catalyst for change and an accepted dimension of self.

Menopause, except as it was embedded in the total cancer experience, did not stand out as a significant threat to how our participants saw themselves. Even our youngest participant, who was devastated by the loss of her ability to have her own children, did not speak of being menopausal as something that called into question her sense of herself as a woman. As mentioned earlier, the most clear statement of menopause as a threat to personal identity came from a participant whose cultural background put a strong value on menstruation as a sign of womanhood. It seems likely that for many North American women menstruation per se is not tied to their identity as a woman.

\section{The power of knowing}

Throughout these interviews, our participants spoke very strongly and eloquently not only of the need to know, but also of the power of knowing. Knowing was rarely a neutral process; it was powerful in both positive and negative ways. It took place within a personal context, and the people who provided or withheld information were critically important to its ultimate impact.

For some participants, the experience of discovering their cancer involved not only the medical investigations, but knowing "inside," often before seeking help of any kind. One woman explained, "From the beginning (I knew). But they told me there is nothing wrong. But I know because I know in myself, so I said to myself, 'Why is that, why are they telling me that there is nothing wrong?"'

The response of the medical system to their concerns set the stage for the relationship that followed. Some women described physicians whom they felt had failed them, had not listened to them when they came in with troubling symptoms, and had devalued their inner sense that something was wrong.

Communicating information and knowledge was another area that received extensive discussion. Each woman remembered how she had been told that she had cancer and how information was shared. Women spoke of the need to feel that there was a relationship for the sharing of knowledge, that their physician was sensitive to the impact of the information he or she was disclosing, and that the physician was not afraid of the response that might follow:

She (gynecologist) did not hesitate about the severity... she told us the worst and best scenario and it was evident in the tone of her voice that we weren't working at the best scenario. She never missed a question. She never avoided a question.

The physician who was seen as sensitive, caring, and attentive to their needs was someone who not only shared information, but situated it within this personal context. He or she respected the woman's need for information, recognized its emotional impact, understood that timing and readiness were important, and that there are levels of information. In the latter respect, one woman observed that there are not only the "facts," but also what gets said about the facts; and that both of these have implications for decisions and how they get made. Withholding information or knowledge was almost always seen as hostile activity. "It's really important (for nurses and doctors) to be up-front with side effects. It's important for them to be very, very informative. Because it can be scary, especially if you hear of other experiences, and the things you read."

Information about the fact that these women would or could become menopausal as a result of their treatment was also situated within the patient-caregiver relationship. Some women felt quite unprepared for this consequence and felt that they either were not told or were told in such vague terms ("your period may stop") that they had no idea what to expect. Timing was also seen as critical - some women observed that, faced with a life-threatening illness and all the decisions one must make immediately about treatment, the reality of a consequence that seems somewhere in an uncertain future can be less than compelling. Reviewing information about menopause after the treatment process is complete was seen as more appropriate. Engaging in a discussion with one's physician about the implications of being menopausal, personally and sexually, was rare in this group of women and then only seemed to happen if instigated by the woman herself.

\section{The power of support}

All of our participants spoke about the impact that the support (or lack of support) from others had on their ability to face what was happening to them. Along with the painful feelings of disappointment and anger that emerged when women spoke of the ways in which health care professionals, friends, or family had let them down, were glowing testimonials to the "incredible," "wonderful" people who saw them through this crisis in a way they never imagined possible. One woman reported that, "We had wonderful support. We live in a small community, we've been here for about 10 years. And not only did I have a lot of visitors in the hospital, people brought over dinners and stuff for the family." Another woman said, "The staff there was so supportive and so wonderful, so gentle, so kind, so understanding, so bending over backwards... ready to listen you out."

The power of support stems from the "fit" between the individual woman's needs and the support she received. For one woman, a strong, unemotional fiancé was seen as a source for her own courage; for another, the apparent lack of warmth and empathy by medical and nursing staff was experienced as uncaring and non-supportive.

For some women, the recovery process involved sorting through when they needed the support of others and when they needed to be alone with their own thoughts and feelings, reclaiming personal space and a renewed sense of autonomy. Caring and being cared for were 
seen as a dynamic process. For some participants, in protecting others, they were also protecting themselves; in helping others (such as their children) to understand what was happening, they were also desensitizing themselves to the frightening implications of their disease and treatment. Support was seen as multidimensional; it involved sharing emotion, knowledge, and experience in many domains.

Most of the discussions of support took place within the context of the cancer experience, but support was also relevant to living with menopause. Especially in the area of sexual intimacy, our participants spoke of the importance of their partner's understanding, gentleness, and willingness to change their sexual practices. Some women expressed disappointment at not being able to please their partners in the way they had in the past, but also great appreciation at the implicit acceptance that their spouses demonstrated in not pressuring them or demanding more. It would appear that support for other menopausal symptoms (e.g., hot flashes) was not generally solicited. As is perhaps the case for women in normal menopause, our participants tended to endure the more troubling symptoms and hope others would either not notice or not comment. In this regard, support groups for menopausal women were seen by some participants as inappropriate because they were composed of women at a different stage of life, with different issues to pursue.

\section{Discussion}

Our interviews with women who were experiencing cancer treatment-induced menopause suggest that it is not, on its own, as significant an issue as we had anticipated. Instead, it was usually described as one dimension of the whole cancer experience, which was a very powerful, life-altering process for all the women with whom we spoke. One reason that menopause may not have emerged as a separate, critical concern is the fact that most of our participants were not in the younger age bracket, most already had children, and most were in long-term stable relationships. In contrast, our youngest participant, without children, spent the greater part of her interview talking about the impact of menopause on her dream of having a family of her own. If our sample had included more women in their twenties and thirties, the emphasis on menopause may have shifted considerably. In spite of this limitation, it seems clear that understanding the meaning of treatment-induced menopause requires an understanding of the larger cancer experience for the individual woman. Menopause plays a role within the process of "getting through" cancer and that differs for each woman. Interestingly, similar categories of "going through" a survival process and "getting through" and back to normal have been identified in independent analyses (Carter, 1993; Shapiro, Angus, \& Davis, 1997).

Within the "getting through" process, menopause has many meanings. It can represent loss - of womanhood, fertility, intimacy, and pleasure - and, as such, it acts as a painful reminder that life will never be the same. It can be seen as something to get beyond, one component in the array of changes that some cancer survivors would like to relegate to an experience that is now over. For others, menopause is a disruption to daily life, but one with which they have learned to live. In this respect, it is reductionistic to speak of treatment-induced menopause as a separate phenomenon or to assess its impact based on the severity of physical symptoms alone.

\section{CancerCare Manitoba is a comprehensive cancer center, which provides services across the spectrum from prevention, early detection, treatment, rehabilitation and palliation to meet the CancerCare MANITOBA ActionCancerManitoba excellence in care for all Manitobans. We strive to prevent, endeavor to cure and are committed to enhancing the quality of life of persons living with cancer.}

Our ambulatory treatment center in Winnipeg provides cancer care at two clinical units where referral and consultation, treatment using a variety of modalities (systemic, surgical, radiation therapy as well as high dose radiation and blood and marrow transplantation) and followup care. Through integral relationships with both the Health Sciences Centre and St. Boniface General Hospital, we care for cancer patients through the trajectory treatment. CancerCare Manitoba is nearing completion of the first phase of a state of the art building that will double clinical space, provide for a new prostate center, create unique space for pediatric and BMT patients and a dedicated patient resource area. We are currently implementing the Oncology Day/Evening Hospital Program to provide cancer treatment services more effectively in the ambulatory setting.

The Oncology Nurse at CancerCare Manitoba is a Registered Nurse who provides holistic cancer care to patients over the spectrum of the oncology experience: assessment, intervention, treatment administration and follow-up and evaluation in the ambulatory setting. Responsibilities include provision of all aspects of chemotherapy administration and other interventions as prescribed by the oncologist, act as a clinical resource and case manager, make pertinent nursing assessments, collaborate with the multidisciplinary care team and provide appropriate interventions, and patient/family counseling and education and their regarding disease, care and treatment planning. We are seeking ideal candidates who are caring professionals possessing excellent technical and patient care skills and a sound knowledge of all aspects of oncology nursing with an emphasis on chemotherapy. Candidates should have excellent interpersonal, oral, and written communication skills and be able to integrate quickly into multidisciplinary patient care teams. Excellent analytical and problem solving skills are also required. Commitment to patient-centered focus, ability to work within a teamwork framework and commitment to ongoing professional development, leadership and self development are assets needed to fulfill the role of the Oncology Nurse. Variable schedule may be required. Candidates must be eligible for registration with the Manitoba Association of Registered Nurses. Baccalaureate of Nursing preferred. CON (c) is an asset. Current BCLS. The Manitoba Nursing Recruitment and Retention Fund may offer assistance with relocation expenses.

Interested and qualified candidates are invited to submit a detailed and current resume, together with a cover letter to: Human Resources, 100 Olivia Street, Winnipeg, Manitoba, R3E 0V9

Email: ardelle.jacques@ cancercare.mb.ca

Fax: (204) 787-2979 
Two aspects of the cancer and menopause experience were particularly salient in all of our interviews - the need for timely, appropriate information and preparation, and the importance of support from family, friends, and medical caregivers.

The process of adaptation to "life after cancer" is often further complicated for women with treatment-induced menopause because they are uncertain or confused about the source of their problem. This seems to be, in part, a result of the lack of information available regarding issues of menopausal status and, in part, a result of inadequate preparation of these women by their health care providers. As noted, most studies dealing with sexual sequelae of cancer treatment focus almost exclusively on disruption to sexual functioning. Other studies indicate that surprisingly few physicians discuss completely the sequelae of cancer therapy, even when they are aware of them (Capone, Good, Westie, \& Jacobson, 1980). It is important to keep in mind that this lack of preparation exists in relation to sequelae that are relatively well-documented - adequate preparation is simply not possible with respect to the psychosocial consequences of treatment-induced menopause, because we know so little about them. In our clinical experience, health professionals' comments that the problems of these women are "in their head" or evidence of malingering or depression indicate a failure to appreciate the multiplicity of symptoms and the process of adjustment related to cancer treatment-induced menopause. Perhaps the most devastating and least helpful advice repeated to us by women was to "accept their situation," an option that promises a profoundly unsatisfying existence and ignores their rehabilitation needs.

Two dimensions of becoming informed stood out in this study: first, that information is powerful (it is not neutral, but contributes, in

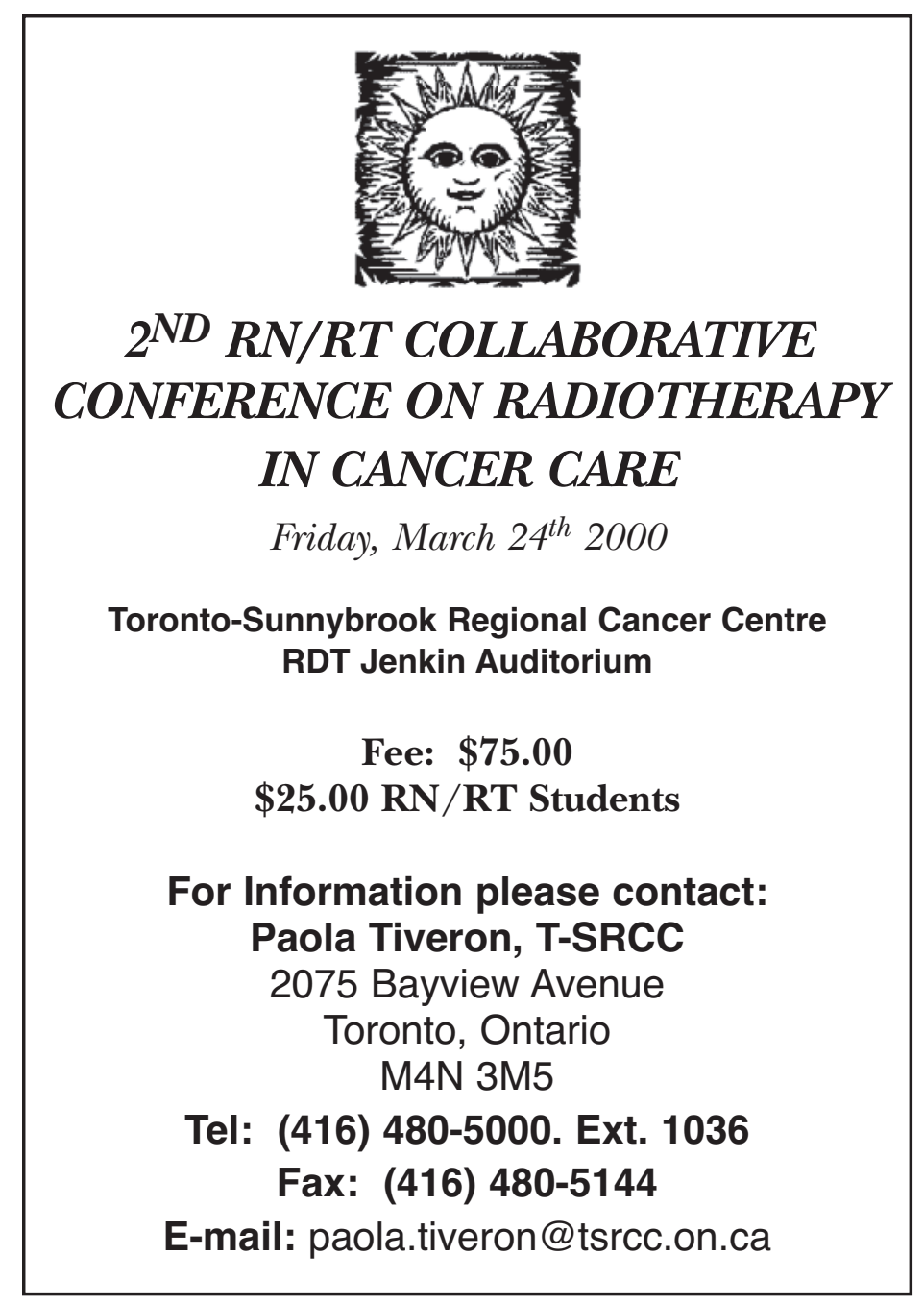

both positive and negative ways, to a person's sense of well-being and control). Second, information exists within relationships - there are the facts and what gets said about the facts, but also by whom and with what kinds of interpersonal messages. In this respect, the process of "getting through" cancer and coping with treatment-induced menopause is influenced both by the quality and timing of information and by the interpersonal context in which it is given and received. In their efforts to provide clear and accurate information, nurses and other health care providers may sometimes forget that their own relationship with the patient plays a significant role in how that information is processed and whether fears and distress are mitigated or, in fact, exacerbated.

The issue of support has become more of a research focus. Research has given more attention to the experiences of the cancer patient's family and friends (Saba, Brown, \& Smith, 1986) and has emphasized the complex ways in which interpersonal relationships affect and are affected by the experience of cancer (Pederson \& Valanis, 1988; Wortman, 1984). In this study, our participants clearly indicated that support from others was critical both in getting through the cancer experience and in adjusting to the long-term effects of treatment-induced menopause. Moreover, support was described as multidimensional (taking a variety of forms) and bidirectional (a dynamic process of giving and receiving). Although many responses were described as supportive, what stood out in these interviews was the importance of the "fit" between the support needed and the support given. This seemed particularly critical in the area of sexual intimacy where sensitivity is high and communication is difficult. Future work could focus on the development of ways to help women and their partners talk about this issue with each other and with

\section{Exploring Bio-Psycho-Spiritual Approaches to Cancer Care}

\section{A workshop dedicated to the memory of Greg O'Connell, MD}

- Friday, April 7, 2000 and Saturday, April 8, 2000 • Hamilton Regional Cancer Centre - Hamilton, Ontario

\section{Educational goals:}

At the end of this program you will:

- have an appreciation of the concept of healing the person versus curing the disease.

- be aware of the importance of multicultural values in cancer care.

- recognize the potential marriage of science and spirituality in treating the whole person

- be aware of some healing techniques utilized in an integrative approach to cancer care

\section{Registration fee:}

- Before March 7, \$165.00

- After March 7, \$195.00 - Daily rate, $\$ 115$

For further information, contact McMaster University Health Sciences Continuing Education, Room 1M7, 1200 Main St. W., Hamilton, ON L8N $3 Z 5$

Tel.: 905-525-9140, ext. 22671;

Fax: 905-572-7099

E-mail: galanor@fhs.mcmaster.ca Website:

http://www-fhs.mcmaster.ca/conted 
relevant health care professionals. The fact that these problems in sexual intimacy are situated both within the experiences of cancer and of premature menopause requires a unique perspective in any program of counselling.

We have seen in this study that treatment-induced menopause not only has physical implications, but also has meaning in terms of each woman's sense of self and her relationships with others (for support and information). We have also seen that their understanding of treatment-induced menopause is embedded within the critical backdrop of their total cancer experience. In this respect, any clinical approach needs to be informed by the complexity of the psychosocial processes underlying successful coping with treatment-induced menopause.

\section{References}

Anderson, B. (1985). Sexual functioning morbidity among cancer survivors: Current status and future research directions. Cancer, 55, 683-691.

Anderson, B., \& Hochler, N.F. (1983). Psychosexual adjustment after vulvar surgery. Obstetrical Gynecology, 62, 457-462.

Atunes, C.M.F., Stoley, P.D., Rosenheim, N., Davies, J., Tonascia, J., Brown, C., Burnett, L., Rutledge, A., Pokenpner, M., \& Garcia, R. (1979). Endometrial cancer and estrogen use. New England Journal of Medicine, 300-309.

Averette, H.E., Boike, G.M., \& Jareel, M.A. (1990). Effects of cancer chemotherapy on gonadal function and reproductive capacity. CA - A Cancer Journal for Clinicians, 40(4),199-209.

Bachmann, G.A. (1994). Nonhormonal alternatives for the management of early menopause in younger women with breast cancer. Journal of the National Cancer Institute Monograph, 16,161-167.

Bianco, A.R., Del Mastro, L., Gallo, C., Perrone, F., Matano, E., Pagliarulo, C., \& DePlacido, S. (1991). Prognostic role of amenorrhea induced by adjuvant chemotherapy in premenopausal patients with early breast cancer. British Journal of Cancer, 63, 799-803.

Brener, P.F. (1988). The menopausal syndrome. Obstetrical Gynecology, 72, 6S-11S.

Canney, P.A., \& Hatton, M.Q.P. (1994). The prevalence of menopausal symptoms in 108 patients successfully treated for breast cancer. Clinical Oncology, 6, 297-299.

Capone, M.A., Good, R.S., Westie, K.S., \& Jacobson, A.F. (1980). Psychosocial rehabilitation of gynecologic oncology patients. Archives of Physical Medical Rehabilitation, 61, 128-132.

Carter, B.J. (1993). Long-term survivors of breast cancer: A qualitative study. Cancer Nursing, 16(5), 354-361.

Cella, D.F. (1987). Cancer survival: Psychosocial and public issues. Cancer Investigation, 5, 59-67.

Cella, D.F., \& Tross, S. (1986). Psychological adjustment to survival from Hodgkin's disease. Journal of Consulting Clinical Psychology, 54, 616-622.

Chapman, R.M., Sutcliffe, S.B., \& Malpas, J.S. (1979). Cytotoxicinduced ovarian failure in women with Hodgkin's disease: I. Hormone function. Journal of the American Medical Association, 242, 1877-1881.

Collaizzi, P.F. (1978). Psychological research as the phenomenologist views it. In R.S. Valle \& M. King (Eds.), Existential phenomenological alternatives for psychology (pp. 48-71). Oxford University Press: New York.

Couzi, R.J., Helzlsouer, K.J., \& Fetting, J.H. (1995). Prevalence of menopausal symptoms among women with a history of breast cancer and attitudes toward estrogen replacement therapy. Journal of Clinical Oncology, 13, 2737-2744.

\section{Implications for nursing}

Nurses in clinical settings need to be aware of the potential for treatment-induced menopause and the consequent difficulties for some women. Good assessment skills are essential, enabling nurses to identify problems and to open discussion with these women. Education, both before and after treatment, is a critical element in helping women understand and cope with menopausal symptoms. In this regard, nurses must know their resources (relevant workshops, programs, and a rapidly-growing popular literature) and be prepared to make appropriate referrals when necessary.

Dewhurst, C.J. (1976). Frequency and severity of menopausal symptoms. In S. Campbell (Ed.), The management of the menopause and postmenopause years (pp. 25-27). Lancaster, England: MTP Press Ltd.

Fenlon, D. (1995). Menopause: A problem for breast cancer patients. European Journal of Cancer Care, 4, 166-172.

Hubner, M.K. (1989). Cancer and infertility: Longing for life. Journal of Psychosocial Oncology, 7(4), 1-19.

Jamison, K.R., Wellisch, D.K., \& Pasnau, R.O. (1978). Psychosocial aspects of mastectomy: I. The woman's perspective. American Journal of Psychiatry, 135(4), 432-436.

Madsen, B.L., Giudice, L., \& Donaldson, S.S. (1995). Radiationinduced premature menopause: A misconception. International Journal of Radiation Oncology, Biology Physics. 32, 1461-1464.

McPhail, G. (1999). Menopause as an issue for women with breast cancer. Cancer Nursing, 22, 164-171.

Moadel, A.B., Ostroff, J.S., Lesko, L.M., \& Bajorunas, D.R. (1995). Psychosexual adjustment among women receiving hormone replacement therapy for premature menopause following cancer treatment. Psycho-Oncology, 4, 273-282.

Pederson, L.M., \& Valanis, B.G. (1988). The effects of breast cancer on the family: A review of literature. Journal of Psychosocial Oncology, 6, 95-188.

Pritchard, K.I. (1996). 19th annual San Antonio breast cancer symposium. Current Oncology, 3(4), 252-254.

Psarakis, S., Devlin, M.C., \& Beckerson, L. (1990). Women and menopause: A contemporary perspective. SIECCAN Journal, 6(2), 21-26.

Saba, D., Brown, J., \& Smith, C. (1986). The male role and mastectomy: Support groups and men's adjustment. Journal of Psychosocial Oncology, 4, 19-31.

Schiam, W.S. (1985). Breast cancer surgeries and psychosexual sequelae: Implications for remediation. Seminars in Oncology Nursing, 1(3), 200-205.

Shapiro, S.H., Angus, L.E., \& Davis, C.S. (1997). Identity and meaning in the experience of cancer: Three narrative themes. Journal of Health Psychology, 2(4), 534-549.

Shover, L.R. (1988). Sexuality and cancer: For the woman who has cancer and her partner. New York: American Cancer Society, Inc.

Snyder, G.M., Sielsch, E.C., \& Reville, B. (1998). The controversy of hormone-replacement therapy in breast cancer survivors. Oncology Nursing Forum. 25, 699-706.

Tamlyn-Leaman, K. (1995). Adult cancer survivorship: issues and challenges. Canadian Oncology Nursing Journal. 5(2), 45-47.

Tross, S., Holland, J.C., Bosl, B., \& Geller, N. (1984). A controlled study of psychosocial sequelae in cured survivors of testicular neoplasms. Proceedings of the American Society for Clinical Oncology, 3, 74.

Wortman, C.B. (1984). Social support and the cancer patient: Conceptual and methodologic issues. Cancer, 53(10) (Supp.), 2339-2360. 